\title{
DE QUE É CAPAZ O EU-MULTICULTURAL?
}

\author{
LISETE BAMPI ${ }^{*}$
}

\begin{abstract}
Espinosa dizia: não se sabe do que um corpo humano é capaz, quando se liberta das disciplinas do homem. E Foucault: não se sabe do que o homem é capaz "enquanto ser vivo", como conjunto de forças que resistem.
\end{abstract}

(Gilles Deleuze, 1995)

\begin{abstract}
RESUMO: Podemos visitar uma escola de educação infantil, de ensino fundamental ou médio e reconhecermos uma educação para a produção de sujeitos diferentes, orientados a conduzirem as suas ações de um modo multicultural. Neste artigo, analiso como o governo do multiculturalismo realiza-se pelo funcionamento das tecnologias do eu - reflexivo, sentimental, cidadão e livre -, operadas pelo dispositivo etnomatemático. Mostro como essas tecnologias combinam-se com outras técnicas e práticas específicas de governo da subjetividade multicultural. Aponto para a produtividade analítica que a perspectiva foucaultiana oferece para pensar outras possibilidades de experimentar a educação no presente.
\end{abstract}

Palavras chaves: Tecnologias de governo. Dispositivo. Discurso. Multiculturalismo. Foucault.

\section{WHAT IS THE MULTiCULTURAL SELF CAPABLE OF?}

ABSTRACT: Whoever visits a pre-, elementary or high school will recognize an education aimed at producing different subjects, mentored to conduct their actions in a multicultural way. This paper analyzes how multiculturalism government uses the functioning of technologies of the - reflexive, sentimental, citizen and free - self, operated by the ethnomathematical device. It shows how these technologies are combined with other specific techniques and practices of multicultural subjectivity government. It points out the analytical productivity that the Foucaultian perspective offers to think of other possibilities to experiment education in the present.

Key words: Government technologies. Device. Speech. Multiculturalism. Foucault.

Doutora em Educação e professora do Departamento de Ensino e Currículo da Universidade Federal do Rio Grande do Sul (UrRGS). E-mail: lisete.bampi@ufrgs.br 


\section{De QUOI LE “Moi-MUlticulturel” EST-IL CAPABLe?}

RÉSUMÉ: Il suffit de visiter une école, un lycée ou un collège pour reconnaitre une éducation visant la production de sujets différents, orientés à conduire leurs actions de manière multiculturelle. Cet article analyse comment le gouvernement du multiculturalisme a recours aux fonctionnement des technologies du moi - réflexif, sentimental, citoyen et libre--, opérées par le dispositif ethmomathématique. Il montre comment ces technologies se combinent à autres techniques et pratiques spécifiques de gouvernement de la subjectivité multiculturelle. Il désigne la productivité analytique offerte par la perspective foucaldienne pour penser d'autres possibilités d'expérimenter l'éducation dans le présent.

Mots-clefs: Technologies du moi. Dispositif. Multiculturalisme. Foucault.

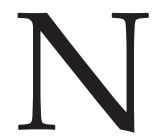

o campo educacional contemporâneo, identificamos a necessidade de produzir sujeitos diferentes, orientados a conduzirem as suas ações de um modo multicultural. Com efeito, torna-se necessário reencontrar em um indivíduo ou em um modo de existência, referentes gerais que permitem assimilálos a outros. Trata-se de um discurso que, combinado com as mais diversas formas de pedagogias - desde as cidadãs, construtivistas, libertadoras, emancipatórias, até aquelas que vêm sendo chamadas de novas tecnologias ${ }^{1}-$, atualiza metanarrativas que operam na produção de identidades naturalizadas. Todos iguais, todos diferentes: este é o "lema multicultural que as escolas deveriam reproduzir tanto entre as suas paredes quanto fora delas" (Larrosa, 2002a, p. 73). ${ }^{2}$

Estes investimentos na diversidade cultural também podem ser encontrados na publicidade, na televisão, no cinema, no mercado da moda, interpelando, representando e orientando os indivíduos a agirem como se fossem eus de um tipo particular. As mais diversas maquinações do eu (Rose, 1996) colocam em jogo um ser que deve ser anexado a um projeto de identidade. No campo da educação matemática, a relevância de problematizar as diferenças multiculturais e as múltiplas identidades vem sendo expressa pela etnomatemática.

Neste artigo, mostro um dos resultados obtidos na pesquisa em que analisei o governo do multiculturalismo operado pelo dispositivo etnomatemático. ${ }^{3}$ Para tanto, constituo a etnomatemática como um dos dispositivos de governo multicultural. ${ }^{4}$ Argumento como esse dispositivo operacionaliza tecnologias ${ }^{5}$ de governo do $\mathrm{eu}$ - reflexivo, sentimental, livre e cidadão -, orientando os indivíduos a exporem o seu eu e a modificarem as suas atitudes em relação a si mesmos e aos outros de um modo reflexivo, sentimental, livre e cidadão. Na medida em que essas tecnologias cruzamse, combinam-se com outras técnicas - da própria aprendizagem, da autoconfiança, da coragem, da autoestima, de orgulho, satisfação e felicidade, de consciência cultural, política e social, da livre escolha, de responsabilidade e de decisão, da participação ativa e da cidadania democrática -, que se atravessam, se afastam e se repetem e, assim, constituem 
o eu-etnomatemático. Pode-se, a partir daí, encontrar o funcionamento da reflexão, dos sentimentos, da liberdade e da cidadania como tecnologias de governo da subjetividade multicultural. Por fim, argumento sobre a produtividade analítica que a perspectiva foucaultiana oferece para pensar outras possibilidades de experimentar a educação no presente.

A etnomatemática, como um dos dispositivos multiculturais de governo, pelo que é capaz de fazer, aproxima-se de si mesma e de outros dispositivos, tais como o do marketing. As práticas etnomatemáticas ${ }^{6}$ estão inscritas em jogos de poder-saberverdade, encontrando-se ligadas às configurações de saber que delas emergem, mas que, do mesmo modo, as condicionam, realizando formas de subjetivação. $\mathrm{O}$ dispositivo etnomatemático faz funcionar tecnologias de governo: reunindo, misturando, capturando, definindo, selecionando uma heterogeneidade de práticas, discursos, procedimentos e técnicas que compõem as tecnologias do eu-multicultural. O dispositivo etnomatemático articula tais tecnologias a uma racionalidade multicultural, fazendo com que os resultados obtidos desdobrem-se em modos etnomatemáticos de governo do $\mathrm{eu}$.

\section{Reflexivo}

A reflexão orienta os indivíduos a reconhecerem-se como sujeitos de suas próprias ações e das ações dos outros sobre si mesmos. A tecnologia do eu-reflexivo-etnomatemático combina-se com técnicas pelas quais os indivíduos são conduzidos a refletirem sobre a sua própria aprendizagem. Para que o aluno possa refletir sobre a sua própria aprendizagem, torna-se necessário criar espaços para a reflexividade que conduzam à "oportunidade para a autocrítica" (Vithal, 2000, p. 11). É dessa forma que são criadas situações pelas quais o aluno possa "mover-se de sua etnomatemática para a matemática acadêmica" (Benn, 1997, p. 182).

Se uma das tarefas etnomatemáticas consiste em fazer com que os indivíduos se tornem sujeitos-reflexivos, essa tarefa será operacionalizada por meio de técnicas de fazer falar: "trabalho em grupo" (Benn, 1997, p. 94); "reflexão através de diários" (ibid., p. 182); situações de aprendizagem empreendidas por meio do "diálogo" (Vithal, 2000, p. 11). Reflexão e diálogo se combinam, conduzindo os indivíduos a narrarem os acontecimentos de suas vidas em espaços que possibilitam a condução do $e u$. Motivar os indivíduos a expressarem as suas ansiedades e dificuldades matemáticas, a compreenderem a si mesmos, a julgarem a si mesmos; maximizar modos de ser e agir; produzir capacidades e habilidades etnomatemáticas: eis alguns meios para fazer funcionar tecnologias multiculturais no governo do eu-reflexivo.

O diálogo, mais do que um modo de exercer democraticamente a pedagogia, de solucionar problemas, de construir conhecimentos etnomatemáticos, funciona 
como uma técnica de governo da própria aprendizagem que, combinada com a reflexão, faz falar, direciona ações e propicia que os indivíduos se autoconduzam de uma forma que venham a dar sentido as suas condutas em relação as suas crenças, atributos pessoais e sentimentos como sujeitos dessas ações. É característica dos objetivos etnomatemáticos a compreensão de que, pela reflexão sobre os seus sentimentos, relacionados ao saber matemático, o indivíduo assegura um entendimento de si mesmo, desenvolvendo atitudes cooperativas que diminuam o sexismo, o racismo e os conflitos de classe. Ao atuar de um modo reflexivo, o indivíduo age sobre os seus sentimentos relacionados à matemática, sobre as minúcias de sua vida diária, acentuando suas chances para melhorá-la. A reflexão é uma tecnologia do eu que possibilita transformar e produzir uma experiência de si mesmo, ${ }^{7}$ na medida em que orienta os indivíduos a refletirem, a interrogarem-se sobre sua relação com a matemática, regulando-se e modificando a si mesmos.

A incitação a refletir criticamente sobre tudo encontra suas justificativas em crenças, tais como a de que, por meio de uma educação etnomatemática, o indivíduo alcançará um estado de "paz total", que "depende essencialmente" de cada um se "conhecer e se integrar na sua sociedade, na humanidade, na natureza e no cosmos" (D'Ambrósio, 1998, p. 6). Essa educação terá como prioridade "atingir o estado de PAZ INTERIOR" mediante práticas que conduzam o indivíduo a "conhecer a si próprio, ter respeito por si próprio e amar-se" (idem, 2000, p. 6). Da perspectiva do governo, entretanto, pode-se dizer que essas crenças estão atravessadas por aquelas mesmas tecnologias que atribuem à educação a tarefa de esclarecer consciências, produzindo sujeitos capazes de salvarem a si mesmos e a humanidade pelo acesso ao poder da razão. O indivíduo será conduzido a agir, avaliando suas ações de uma forma que antecipe possíveis transgressões, regulando sua conduta de acordo com um modo de existência que o conduza a alcançar um estado de paz interior.

As práticas etnomatemáticas, em seus efeitos, (re)atualizam aquelas tecnologias cristãs que conformam em um espaço interior tudo aquilo que tem a ver com a moral, o mental e a virtude. É constituída uma técnica do interior; é como se fossem descobertas uma profundidade e uma estrutura intrínsecas aos indivíduos. Educar-se etnomatematicamente seria orientar, controlar, ativar algo que nasce e se expande no interior do indivíduo. Esse governo do interior é configurado, também, pelo efeito que uma técnica do social, político e cultural opera sobre ele, definindo como o espaço da sociedade se transforma e é transformado em um espaço no qual, antes de mais nada, os indivíduos são compreendidos como se fossem eus equipados com um domínio interior.

Pela reflexão, pode-se ver, também, as identidades operando neste processo de sujeição de um eu que precisa matematizar-se e identificar-se social, cultural e politicamente, reconhecer-se como um cidadão. Os objetivos políticos da cidadania e da justiça social são estendidos e (re)atualizados no terreno do eu que, para tornar-se 
reflexivo, deverá etnomatematizar-se. A linha entre subjetividade e sujeição é atravessada quando se sujeita a si mesmo e se alinha metas pessoais com uma noção de bem social. Adquirir cidadania e liberdade requer, aqui, um trabalho sobre o eu.

A reflexão é orientada para condutas consideradas problemáticas, que deverão ser modificadas pela apreensão do saber matemático. A falta de confiança, de entusiasmo e de sucesso na matemática torna-se um problema que, parece, será solucionado por práticas de aprendizagem que levem em conta a cultura dos indivíduos. Favorecer a autoconfiança é uma forma de sujeitar os indivíduos, tornando-os inclinados a aprender por si mesmos os propósitos desta técnica, qual seja: etnomatematizar-se. A reflexão traz à tona as suas dificuldades, com a sua falta de autoconfiança, e as oportunidades para adquiri-la por meio de capacidades e habilidades que serão criadas, tais como: valorizar a matemática local, possuir dignidade e reafirmar-se culturalmente.

A reflexão opera das mais diversas formas, atravessando e sendo atravessada pelas mais variadas técnicas, dependendo do modo com que os indivíduos são identificados nos novos espaços multiculturais de governo. Podemos tomar como exemplo os espaços da exclusão, nos quais ações multiculturais são operadas e estendidas às famílias e às comunidades com o objetivo de empoderar seus sujeitos, tornando-os autoconfiantes e autônomos. Para se constituir como um sujeito capaz de refletir, o indivíduo precisa instaurar uma relação com o seu eu, mediante formas multiculturais de aprender matemática que deverão torná-lo capaz de autonomia e poder. Este eu-empoderado não é nada mais, nada menos, que o resultado das ações que exerce sobre si mesmo e que são exercidas sobre as suas.

\section{Sentimental}

Aquilo que na ordem da conduta multicultural parece constituir objeto de preocupações sociais, políticas e culturais, tais como o respeito e a valorização às diferenças, é transformado em questão que envolve a produção de características pessoais e internas aos indivíduos. No entanto, não é menos indispensável, nessa ordem, reconhecer o exercício de uma tecnologia multicultural. Produzir sujeitos que, acima de tudo, sintam-se orgulhosos de suas culturas e de pertencer a um grupo cultural específico requer ações que ativem sentimentos - de felicidade, de segurança, de satisfação, de autoestima. Para tanto, são operacionalizadas práticas que possibilitam aos indivíduos compreenderem-se como carentes desses sentimentos. Para suprir esta necessidade, os indivíduos aprenderão a se relacionar consigo e com os saberes matemáticos de um modo sentimental.

A autoestima é toda uma maneira de se constituir como um sujeito, manifestando a forma da relação que o indivíduo etnomatematicamente educado manterá 
consigo mesmo e com seus saberes e os tipos de ações que exercerá sobre si mesmo para que se sinta autoestimado. As práticas de constituição da autoestima estão articuladas a discursos que se referem à necessidade de maximizar o potencial humano a partir da produção de certa harmonia emocional e de uma eficiência cognitiva. A autoestima é uma das técnicas de controle contemporâneas que conduz os indivíduos, nos lugares mais mundanos, a identificar a sua subjetividade. As formas pelas quais os indivíduos constituem a si mesmos como sujeitos culturalmente responsáveis, de poderes, de autorrealização, capazes de sentimentos multiculturais, de superar barreiras de aprendizagem, alcançando êxito e sucesso na matemática, são o resultado da combinação de práticas que tomam modos de existência como o seu objeto.

Ora, como não seriam etnomatemáticos os saberes por excelência para solucionar problemas causados pela falta de autoestima em uma prática, na qual se considera as matemáticas locais como "uma valiosa fonte de um sentimento de autoestima e de confiança, ingredientes indispensáveis de uma carreira acadêmica exitosa" (Kufakwami, 1992, p. 2)? A falta do saber matemático, parece, atinge a todos do mesmo modo, já que a "matemática afeta a vida em todos os seus aspectos" (Croom, 1997). Convém, então, perguntar: como não seriam etnomatemáticas, as práticas por excelência, a solução para a falta, já que elas são apresentadas como um "estudo da evolução cultural da humanidade"? (D'Ambrósio, 1993, p. 100). ${ }^{8}$

Daí, a importância dos saberes matemáticos locais na condução do eu, cujas técnicas transferem problemas da pedagogia para questões internas aos indivíduos, as quais objetivam aumentar a autoestima e estimular o interesse na matemática. Por meio dessas técnicas de ativar o interesse é produzida uma relação do eu-paracom-o-eu, pela qual os indivíduos passam a se entender como eus que, mediante a aprendizagem da matemática, podem modificar os seus sentimentos em relação a si mesmos e aos outros. Quando a necessidade de estimular o interesse na matemática é objetivada, um campo de inteligibilidade é produzido e a partir dele a autoestima é pensada e operacionalizada.

Na medida em que os indivíduos expressam os seus sentimentos e sua crença de que a aprendizagem matemática aciona tais sentimentos, condutas desejáveis são constituídas e subjetividades, às quais se pode aspirar, são conformadas. As condições para a produção de sujeitos desejáveis - a criança que expressa seus sentimentos, que possui autoestima e orgulho cultural - são governadas por meio de técnicas que, simultaneamente, identificam e distinguem. A própria capacidade dos indivíduos de estimarem a si mesmos torna-se uma questão de governo. A autoestima transforma a "relação do eu-para-com-o-eu em uma relação que é governável" (Cruikshank, 1999, p. 89).

O orgulho, a satisfação e a felicidade dos indivíduos, entendidos como formas de ação que eles são capazes de exercer sobre si mesmos, requerem a combinação 
de técnicas que os conduzam a olhar e a agir sobre o que ocorre em seu interior. A atitude etnomatemática que o indivíduo será orientado a adquirir está relacionada com sentimentos multiculturais. Para tanto, é preciso criar condições que conduzam a essa atitude, possibilitando ao indivíduo exercer uma relação sentimental consigo mesmo, que é ativada pelo "diálogo" e através de "discussões", práticas pelas quais os indivíduos falam de seus "sentimentos" que se tornam "motivo" de "preocupação" (Knijnik, 1996, p. 40).

As práticas etnomatemáticas caracterizam-se pela possibilidade que oferecem a cada indivíduo de falar de seus sentimentos. Tomo, como exemplo, aquelas práticas em que os indivíduos dizem-se "satisfeitos" por já lerem algumas "placas" e "felizes" em "aprender os números" (Monteiro, 1998, p. 145). A atitude do sujeito etnomatematizado em relação a si mesmo e a maneira pela qual garante sua própria satisfação, no que diz respeito às suas aspirações e sentimentos, são elementos constitutivos da felicidade. Esta, no entanto, não será compreendida, simplesmente, como uma forma pela qual os indivíduos expressam um sentimento proporcionado por uma capacidade matemática adquirida. Em sua forma técnica, ela é um modo de exercer poder sobre si mesmo, conformado pela produção da necessidade de adquirir essa capacidade.

Encontram-se práticas etnomatemáticas orientadas por uma pedagogia que, além de considerar os aspectos culturais no ensino da matemática, tem por "finalidade" entender questões, tais como: a "matemática desperta a sensação de temor, de falta de confiança e, inclusive, de ódio", especialmente, nas "pessoas jovens que não têm êxito na matemática"; para "alguns, inclusive, provoca a sensação de opressão e de dominação por parte de um desconhecido" (Ismael, 1998, p. 66). Por um lado, essa pedagogia orienta os indivíduos a aprenderem a "gostar de matemática, perdendo o medo de perguntar, de dizer de suas dúvidas e dificuldades"; e, por outro, se eles dizem sentir-se "inseguros", é porque "práticas sociais" - consideradas, pelos grupos, "verdades inquestionáveis" - foram problematizadas. Assim, entende mostrar-se "atenta não só para os aspectos cognitivos" do processo pedagógico, mas também para os "sentimentos" (Knijnik, 1996, p. 40).

Ao falarem de seus sentimentos, os indivíduos efetivam e modificam ações sobre si mesmos, expressando não somente sua insegurança, mas também sua angústia, aflição e ansiedade. Dessa forma, esses sentimentos são tecnologizados, tornando-se objetos de regulação etnomatemática. Nessas práticas, tão delicadas e sentimentais, entretanto, estão comprometidos todo um campo de saber e todo um conjunto de técnicas de poder. As culturas locais são captalizadas pela combinação de técnicas que objetivam e constituem modos de se relacionar com os saberes matemáticos, orientando o indivíduo a instaurar uma relação sentimental consigo mesmo e com esses saberes. 
Se os indivíduos sentem-se "angustiados", "aflitos" e "ansiosos", em relação à "insuficiência" de seus conhecimentos matemáticos e reconhecem que isto prejudica a sua "própria capacidade" para aprender, discussões e diálogos, então, são estabelecidos em torno de seus "temores" (Knijnik, op. cit., p. 40-42). O dispositivo etnomatemático combina a técnica de fazer falar, que racionaliza os saberes, com a tecnologia do sentimento que os subjetivam. É um controle sentimental que estabelece sobre os indivíduos uma regulação, através da qual eles serão orientados a tornarem-se capazes de modificar as suas atitudes em relação a si mesmos e a seus saberes, conformado em um modo sentimental etnomatematizado de existir. Na medida em que esses sentimentos multiculturais são operados por um dispositivo de governo, a necessidade de sentir orgulho cultural, de propiciar felicidade por uma educação que enfatiza as diferentes culturas e as matemáticas locais será compreendida como elemento técnico pelo qual a conduta é regulada. Ao que parece, não estamos muito longe daquelas estratégias modernas pelas quais era fácil exportar a cultura ocidental com a convicção de que se estaria levando a verdade, a cultura e a felicidade aos povos miseráveis; tampouco, daquele tempo em que a educação aparece como uma "missão civilizadora" e como a "causa nobre" a que os pedagogos dedicavam seus melhores esforços para oferecer aos povos ditos inferiores os dons da nossa ciência (Larrosa, 2002b, p. 71).

As práticas pelas quais o indivíduo se constitui como um sujeito consciente e batalhador não operam universalizando as suas ações; ao contrário, funcionam por meio de técnicas que individualizam essas ações, que moldam e até podem lhes dar uma resplandecência singular pela forma como definem racionalmente o que convém fazer e como se deve fazer. Os indivíduos tornam-se objeto de um saber que os diferencia, os qualifica e os capacita, colocando-os em uma situação de exame constante de si quando falam de seus "planos futuros": "eu tenho que abrir meus horizontes, partir pra uma vida mais digna, tentar um estudo, uma faculdade. (...) Sair, conhecer um pouco as coisas"; quando contam das "mudanças em seus cotidianos", identificando-se como "os soldados, os batalhadores" de uma "realidade que precisa acontecer no nosso Brasil, começando pela educação"; quando dizem a si mesmos: "eu sou eternamente um soldado batalhador" (Knijnik, 1996, p. 23). Estamos bem longe de um governo que tenda a sujeitar todos os indivíduos do mesmo modo sob uma regra universal. Muito pelo contrário, as práticas etnomatemáticas, operadas por um dispositivo, ajustam e modulam suas técnicas conforme a circunstância dada. E, para isso, não têm necessidade de algo como uma lei geral, basta uma prática que, levando em conta princípios gerais, guie a ação de acordo com o contexto em função de seus próprios fins. As ações dos indivíduos são conduzidas de uma forma que estes venham a se reconhecer como eus-etno-identificados, orientados a identificar a sua subjetividade em uma identidade reconhecível, fixada em padrões etnomatemáticos. Este regime do eu é caracterizado em termos de 
uma "identidade a ser revelada, descoberta ou trabalhada". Trata-se de um processo de "maquinação do $e u$ " que precisa ser reconhecido como "um regime recente de subjetivação" (Rose, 1996, p. 39).

Tornar-se um sujeito consciente culturalmente é reencontrar-se com um passado esquecido, identificar o que lhe é diferente e torná-lo próximo, resgatar saberes matemáticos escondidos, estabilizando uma identidade supostamente perdida. Para se constituir como um sujeito consciente culturalmente, o indivíduo converterá em algo próprio o que não lhe é familiar, transformando a sua atitude para consigo mesmo e para com o outro, tornando-se capaz de ações de transformação. A consciência crítica e a capacidade transformadora, uma mente ampla e aberta, formas de pensar mais tolerantes, solidárias e democráticas: estas são as qualidades que os indivíduos devem adquirir e que, mediante uma aprendizagem que contextualiza os saberes matemáticos, práticas etnomatemáticas se propõem a (re)produzir tanto nas escolas, quanto fora delas. Deixando de lado a vontade etnomatemática de construir uma autêntica sociedade etnomatematizada, é preciso compreender que essas qualidades, quando ativadas em espaços de governo, não são nada mais, nada menos que técnicas de produção de embates entre diferentes forças, meios doces e sutis de regulação dos sentimentos, formas de governo etnomatematicamente controladas.

Trata-se da produção de um abismo entre um mundo interior e um exterior, conformada na constituição de uma subjetividade etnomatematizada. Talvez fosse importante perguntar pela natureza desse controle interior: seria cultural? Quem sabe biológico ou social? Mesmo que a pedagogia etnomatemática seja atravessada por referências psicológicas, parece que alguma coisa nasce e desenvolve-se nesse interior. Desenvolvimento que a etnomatemática ativará, educando, orientando e desempenhando um papel constitutivo na produção da subjetividade multicultural sentimental.

\section{Cidadão}

A cidadania racionaliza e faz funcionar a produção de indivíduos conduzidos a se reconhecerem como cidadãos que não somente adquirem direitos e deveres sociais e políticos, mas também um conjunto de responsabilidades éticas para com suas comunidades. O governo da cidadania é estendido aos grupos e às comunidades pela produção da necessidade de acesso ao saber matemático, orientando a produção de um sujeito que identifica seus desejos e metas pessoais com os da sociedade como um todo: um sujeito-cidadão-participativo com "poderes de liberdade" (Rose, 1999).

Os espaços das comunidades múltiplas e da diversidade cultural são (re)configurados por uma variedade de técnicas que fornecem os meios para a produção de sujeitos que se reconhecem como participantes ativos e cidadãos democráticos. Aqui, o cidadão ativo é aquele que sabe conduzir a si mesmo, capitalizando 
sua própria existência de um modo eficaz e autônomo. A importância das atividades de sala de aula, das atitudes e comportamentos dos professores, dos modos de exercício de sua pedagogia, terá uma ampla abrangência na constituição do sujeito-cidadão. Eis como atuará um professor-cidadão-etnomatematizado: a mesma aprendizagem deverá torná-lo capaz de se autogovernar pelo governo dos outros.

As salas de aula, parece, funcionam como um microcosmo 9 de uma sociedade perfeitamente etnomatematizada, na qual os indivíduos encontram-se reunidos pelo exercício de regras comuns, afirmadas nas relações que definem com o seu eu e com aquilo que pode guiá-lo de dentro. O controle por meio das atividades já não repousa mais na diretividade do professor, mas no modo com que utiliza as suas ações na condução das ações dos estudantes, objetivando torná-los sujeitos de suas próprias ações. Dupla exigência desse governo da atividade etnomatemática: em primeiro lugar, regular, de forma eficaz, um modo de ser e agir como um professor-democrático; em segundo, por esta regulação, conformar uma conduta reconhecível e reconhecida como cidadã-democrática-responsável.

A vontade etnomatemática de ajudar os indivíduos a modificarem a si mesmos, transformando-os em cidadãos, precisa ser equilibrada com a condição necessária de que eles mesmos se ajudem. A subjetividade do sem cidadania precisa ser contrabalançada com a sua sujeição. Por outro lado, essa técnica cidadã (re)modela o problema da cidadania como um problema de exclusão cultural. Os modos de exclusão são confrontados com técnicas cidadãs de inclusão. Estes sujeitos abjetos - o marginalizado, o excluído, o não cidadão - são (re)organizados espacialmente. O território da exclusão é (re)configurado de forma que tais sujeitos sejam reconhecidos e se reconheçam como se estivessem fora dos circuitos de cidadania. A cidadania combinase com a técnica de empowerment, objetivando que os indivíduos se autogovernem como cidadãos-democráticos, ligando a subjetividade dos indivíduos a sua sujeição cidadã. As metas políticas de cidadania e empowerment são tecnologias práticas que prometem certo tipo de liberdade e justiça social. Estes sujeitos-cidadãos são o objeto e o resultado de uma vontade de empowerment (Cruikshank, 1999).

\section{Livre}

Delimitando caminhos que possibilitem orientar problemas sociais, políticos e culturais, as práticas etnomatemáticas, operadas por um dispositivo de governo, movimentam técnicas que não têm sua origem no Estado. No entanto, governar de um modo multicultural etnomatematizado tem proporcionado a constituição de tecnologias que possibilitam, de forma eficaz e econômica, introduzir objetivos das autoridades políticas no interior das escolhas, necessidades e interesses próprios aos indivíduos. O que é apresentado, aqui, é a ideia de que os indivíduos já possuem 
uma capacidade própria de escolher, atada a um modo livre de agir que, mediante uma etnopedagogia, apenas deveria ser exercitado. Parece que se trata da constituição de um sujeito-livre, "portador de uma faculdade humana fundamental que seria anterior a qualquer determinação social: a capacidade de escolher" (Veiga-Neto, 2000, p. 199).

Uma existência livre, aqui, não pode desenrolar-se sem se adaptar à existência dos outros. As escolhas tornam-se passíveis de negociação, constituindo um modo de regulação das ações livres, permitindo a cada instante que cada um saiba como deve modificar as suas ações. A capacidade de trabalhar colaborativamente, a habilidade de lidar com diferentes pontos de vista, de expressar as suas próprias opiniões, a fim de obter um entendimento mútuo por meio da consideração dos outros, são modos de agir característicos das relações que os indivíduos estabelecerão com os outros e que a pedagogia etnomatemática se propõe a exercitar. Contudo, o que confere importância às capacidades e aos modos de exercê-las é a sua produtividade estratégica pela liberdade. O exercício da liberdade supõe um sujeito livre para escolher. No entanto, para que possa escolher livremente, é preciso empoderá-lo, educando-o etnomatematicamente, tornando-o capaz de negociar e de refletir sobre as suas próprias escolhas.

A negociação, como uma técnica do $e u$, produz as condições pelas quais a liberdade de escolha é conduzida, agora, combinando-se com a avaliação, transformandoas em uma questão de governo do eu, por meio da condução de opções reguladas. Os indivíduos são providos com racionalidades etnomatemáticas para viverem suas vidas de acordo com um regime etnomatemático da escolha. Nesse regime, seus destinos são remodelados como atos de sua escolha dentro de um ambiente que fornece uma pluralidade de possíveis opções, conduzindo-os a se reconhecerem como sujeitos que exercem livremente as suas escolhas.

As práticas etnomatemáticas requerem um sujeito livre para escolher, tal como nos atuais regimes neoliberais de governo. A liberdade subjetivante que atravessa o neoliberalismo, mais do que um mecanismo de domínio econômico, é uma tecnologia eficaz para o funcionamento de um dispositivo multicultural. As tecnologias postas a funcionar pelo dispositivo etnomatemático, mediante o governo da liberdade, também se combinam com uma racionalidade de governo atravessada por técnicas, orientada para uma economia de poder voltada para o lucro em uma escala mundial. ${ }^{10}$ Pode-se dizer que as mesmas tecnologias de livre escolha que atravessam esses regimes, o dispositivo etnomatemático as (re)atualiza, pondo-as a funcionar no governo do eu-livre.

Com efeito, uma coisa são as técnicas de governo do $e u$, outra, são as condutas orientadas por essas técnicas; outra, ainda, é a maneira pela qual se torna necessário conduzir-se como um eu-livre para escolher. Então, convém interrogar: 
existem outras maneiras pelas quais se constitui a si mesmo como um sujeito de livre escolha? A liberdade orienta novas relações entre indivíduos, grupos e comunidades, fazendo com que o indivíduo que age seja reconhecido e se reconheça não somente como agente, mas como sujeito de suas ações. O eu-livre é esculpido por um conjunto (re)atualizado de técnicas de governo que o orienta a agir como sujeito que possui vínculos, obrigações e responsabilidades com um grupo ou uma comunidade. Em sua comunidade, eles devem tornar-se autorresponsáveis e decididos, sujeitos a um modo de ser e de existir conformado a partir da produção de laços familiares, de etnia, de cultura e da produção de ligações entre grupos, movimentos sociais, associações, localidade, entre outros.

Antes de qualquer coisa, os territórios de governo são (re)localizados a partir de uma convivência com a pluralidade cultural (Rose, 1999). Pode-se dizer que a escolha é uma tecnologia política dos indivíduos. Tornar-se um sujeito-democrático depende de atitudes de responsabilidade e de decisão individuais, mas com vistas a um bem social. Os indivíduos são conduzidos a reconhecerem a si mesmos como se fossem parte de uma sociedade, de uma entidade social, de uma nação ou de um Estado (Foucault, 1988b). A liberdade pressupõe a "existência de um sujeito livre de desejos, necessidades, interesses e escolha". Contudo, sua "sujeição é também uma condição de sua liberdade: para que possa agir livremente, o sujeito deve antes ser regulado, guiado e moldado para tornar-se alguém capaz de exercer responsavelmente essa liberdade em sistemas de dominação" (Dean, 1999, p. 165).

Ao constituir a necessidade de educar para a liberdade, fazendo emergir novas racionalidades políticas, o dispositivo etnomatemático põe em funcionamento técnicas sutis de controle das escolhas, vinculando as ações dos grupos e dos indivíduos, através da instrumentalização de sua liberdade regulada. Ao definir seus sujeitos, a racionalidade etnomatemática o faz a partir de um modo multicultural de existir: sujeitos orgulhosos de sua própria cultura, sujeitos confiantes e conscientizados, sujeitos transformadores, cujas condutas são esculpidas por meio de tecnologias, pelas quais suas ações são instrumentalizadas e maximizadas dentro de um campo etnomatemático de governo do eu. A ironia disso tudo talvez esteja em acreditarmos que, ao nos transformarmos em sujeitos conscientes, respeitosos, reflexivos, corajosos, confiantes, sentimentais, participativos, cidadãos, batalhadores, multiculturais, etnomatematizados, estaríamos escolhendo livremente um modo de vida.

\section{Quem sabe...}

Em Foucault, livro do qual extraí a citação que serve de epígrafe para este texto, Deleuze (1995) refere a admiração de Foucault por Bichat, que inventou um novo vitalismo, definindo a vida pelo conjunto das funções que resistem à morte. 
A vida seria a capacidade de extrair do velho uma existência mais afirmativa, rica em possibilidades. O pensamento de Foucault nos possibilita analisar o funcionamento de um dispositivo sem a necessidade de invocar um sujeito centrado, dotado de bons sentimentos e boa consciência, mas em favor de novos modos de vida.

Quem sabe, então, se o dispositivo etnomatemático se transformasse, retirando do velho e do já sabido suas forças produtivas em favor de um modo de vida mais rico, de uma educação mais ativa, de um conjunto aberto de possibilidades e potencialidades educacionais, sem a presença de uma subjetividade já sabida, seja ela reflexiva, cidadã ou livre, fosse possível dar um primeiro passo para livrarmo-nos do sujeito, perturbando um modo de educação que tem em seu centro a tranquilidade de práticas dialogicamente mediadas por um futuro e um passado seguros e asseguradores de uma identidade cultural previsível. ${ }^{11}$

Se o dispositivo etnomatemático se (re)inventasse, atualizando-se em favor do que estamos sendo, talvez fosse possível experimentar modos de existir sem que tenhamos que nos afirmar em uma subjetividade que tenda à estabilidade de um modo de vida, conformado nas leis de um mercado de livre-escolha-etnomatematizado. Quando o dispositivo etnomatemático aciona suas tecnologias, afirmando os direitos de escolha, a felicidade e a satisfação das necessidades de indivíduos que são orientados a agirem como sujeitos-reflexivos-sentimentais-cidadãos-livres, conectados a um grupo cultural identificável, a uma comunidade ou um movimento social, é a vida que emerge como objeto de governo. É em nome da afirmação de uma identidade de vida, das condições de sobrevivência de um grupo identificável ou de uma comunidade específica que esse dispositivo se operacionaliza. Os modos singulares pelos quais os indivíduos vivem suas existências são introduzidos em uma lógica de mercado que os orienta a agir como se estivessem escolhendo livremente o que são, o que devem se tornar, como se sozinhos estivessem escolhendo assumir a sua própria singularidade. No entanto, esse sujeito-etnomatematizado já é em si mesmo efeito de um processo de fabricação, como uma mercadoria qualquer. Ele já é, dentro de si mesmo, uma forma de aprisionar a vida.

A possibilidade da criação de novas subjetividades, que rompam com a lógica identitária, talvez se encontre em um modo de conduzirmos a nós mesmos que pare de tentar descobrir o que nos separa de nós mesmos, de procurarmos por identidades supostamente perdidas, experimentando uma liberdade que se dê na experiência da insegurança e da incerteza. Talvez essa seria uma forma de evitar que a subjetividade seja esculpida à imagem do que já se sabe e se espera, mas em favor de modos de existência capazes de alegrias e tristezas (re)novadas, de paixões e ações criativas, para além do sujeito, seja ele livre, cidadão, autoconsciente, autorreflexivo, entre outras invenções modernas, (re)atualizadas pelas práticas etnomatemáticas. 
Se experimentarmos nos libertar da liberdade, quem sabe possamos, também, começar a nos livrar do Sujeito. Se deixarmos de tentar descobrir o que somos, recusando o tipo de individualidade que nos tem sido imposto durante séculos, talvez fosse possível experimentar o novo, tornando-nos uma obra de arte concebida fora do eu, fazendo falar o que não tem palavra, o pássaro que pousa no beiral, a árvore na primavera e a árvore no outono, a pedra, o cimento, o plástico ${ }^{12}$...

\section{Notas}

1. Fischer (2006, p. 4) problematiza essa expressão, enfatizando que se trata de uma verdade hegemônica de nossa atualidade, "pela qual se privilegia o novo pelo novo, promovendo apagamentos".

2. Parece que se trata da "produção de uma nova identidade" e da "construção de um novo vínculo social em que a diversidade cultural constitua o tecido de uma nova substância ética" (Larrosa, 2002a, p. 73).

3. O material empírico foi constituído de publicações realizadas no período de 1980-2001. O trabalho analítico foi concluído em 2002 (Bampi, 2003). Considerando a extensão e a natureza deste texto, meu objetivo é apresentar os argumentos construídos a partir da análise do material escolhido, que possibilitou demonstrar como, no interior da proposta etnomatemática, se produzem determinados modos do $\mathrm{eu}$. O outro resultado da pesquisa mostra como as identidades e as diferenças etnomatemáticas funcionam como tecnologias de poder-saber. Tendo em vista a produtividade do discurso da etnomatemática, no cenário educacional, nacional e internacional, inicialmente, busquei tal discurso em artigos de revistas especializadas, tais como: A Educação Matemática em Revista, For de Learning of Mathematics, Zentralblatt für Didaktik der Mathematik, Educational Studies in Mathemathics. Consultei as teses e as dissertações, na área da etnomatemática, contidas no Banco de Teses/EDumat, organizado por Dario Fiorentini (CEMPEM/Fe-UnicAmP). Analisei textos publicados em anais de eventos nacionais e internacionais como: CBEm $1-1^{\circ}$ Congresso Brasileiro de Etnomatemática (2000); MEAS1 - The First Mathematics Education and Society Conference (1998); MES2 - The Second Mathematics Education and Society Conference (2000); First International Congress on Ethnomathematics (1998); as publicações do International Study Group on Ethnomathematics (1985-1998), cuja Newsletter divulga, semestralmente, artigos, teses, dissertações, livros e pesquisas produzidas nesta área. Assim, essas produções, referidas em tais publicações, também se constituíram em material de análise. Textos apresentados em conferências, congressos e "aulas virtuais" proferidas na Universidade Virtual Latino-Americana (UVLA), capturados na home page "Etno-amigos de Ubiratan D'Ambrósio", também foram analisados (Bampi, 2003).

4. Entre os usos que Foucault fez do conceito de dispositivo, em alguns momentos, ele o aproxima da noção de tecnologias - tecnologias disciplinares/dispositivos disciplinares, tecnologia panóptica/dispositivo panóptico, tecnologia da confissão/dispositivo da confissão. Pode-se dizer que o mesmo ocorre com as noções de técnicas e tecnologias: algumas vezes elas imitam-se umas às outras; outras, elas apoiam-se e entrelaçam-se, distinguindo o seu campo de ação; mas, acima de tudo, entram em convergência, (re)articulando-se entre si, rearranjando elementos múltiplos e heterogêneos que, dispersamente, emergem em uma função estratégica (Foucault, 1990, 1995a, 1995b).

5. As tecnologias do eu estudadas por Foucault (1995a, 1995b, 1996, 1997) constituem-se em potenciais ferramentas para pensar as práticas contemporâneas de subjetivação.

6. A partir do pensamento de Foucault é possível afirmar que os mais distintos campos de saber-poder são constituídos por discursos, normas, regras institucionais que são sempre 
práticos, ou seja, a "teoria é sempre uma prática" (Fischer, 2002, p. 50). Apoiando-me nesse pensamento, constituo a noção de "práticas etnomatemáticas" que, acionadas por um dispositivo, nos possibilita olhar e dizer coisas diferentes, sobre o pensamento etnomatemático, das que são olhadas e vistas no interior desse pensamento.

7. Refiro-me à noção desenvolvida por Larrosa (1995).

8. Em Bampi (1999), é desenvolvida uma análise sobre a vontade de totalização do discurso da educação matemática, sobretudo, viabilizada pela etnomatemática.

9. Em Bampi (2003), encontra-se uma análise detalhada dessas práticas.

10. Tomo como exemplo o mercado da moda ou da publicidade e investimentos empresariais referidos em Bampi (2003).

11. Por mais que o discurso etnomatemático atual tenha se alterado, objetivando analisar as relações de poder que ocorrem dentro dos grupos culturais e que buscam não fixar uma identidade social, reconhecendo as relações produzidas em cada grupo cultural - tais como as configuradas, por exemplo, por gênero, raça e pelas relações étnicas, objetivando identificá-las, também, na constituição das identidades sociais -, ele opera elementos sustentados por uma lógica moderna. As identidades não são produzidas somente em termos de uma história de vida, de um passado, de desejos, de hábitos, de formas comuns de raciocinar e de calcular; mas a partir de uma relação dialética com o seu Outro, delimitando um dentro e um fora (Bampi, 2007). Mesmo as produções atuais, que buscam aproximar analiticamente as pesquisas em etnomatemática do pensamento de filósofos da diferença, ainda funcionam na lógica da representação. Existe um abismo teórico, uma fissura para se analisar ou pensar as identidades. A noção de cultura é uma invenção moderna que se torna técnica-chave do governo, por meio das identidades etnomatemáticas, atualizando uma trajetória representacionista.

12. Este parágrafo foi escrito aproveitando-se ideias e fragmentos contidos, respectivamente, em Larrosa (2002b), Foucault (1988b) e Calvino (1990).

\section{Referências}

BAMPI, L. O discurso da educação matemática: um sonho da razão. 1999. 119f. Dissertação (Mestrado em Educação) - Faculdade de Educação, Universidade Federal do Rio Grande do Sul, Porto Alegre.

BAMPI, L. Governo etnomatemático: tecnologias do multiculturalismo. 2003. 200f. Tese (Doutorado em Educação) - Faculdade de Educação, Universidade Federal do Rio Grande do Sul, Porto Alegre.

BAMPI, L. Ordenando poder-saber: produção de identidades e hierarquização de diferenças. Educação E Realidade, Porto Alegre, v. 32, n. 1, p. 25-42, jan./jun. 2007.

BENN, R. Adults count too: mathematics for empowerment. Leicester: National Institute of Adult and Continuing Education, 1997.

CALVINO, I. Seis propostas para o próximo milênio. São Paulo: Cia das Letras, 1990.

CROOM, L. Mathematics for all students. In: Tentracosta, J.; Kenney, J. (Ed.). Multicultural and gender equity in the mathematics: the gift of diversity. Reston: NCTM, 1997. p. 1-9. 
CRUIKSHANK, B. The will to empower: democratic citizens and other subjects. New York: Cornell University, 1999.

D'AMBROSIO, U.A educação matemática e a reincorporação da matemática à história e à filosofia. In: SEMINÁRIO INTERNACIONAL DE EDUCAÇÃO MATEMÁTICA DO RIO DE JANEIRO, 1., 1993, Rio de Janeiro. Anais... Rio de Janeiro: ufrJ, 1993. p. 91-104.

D'AMBROSIO, U. Resumo das aulas virtuais dadas no curso sobre "Etnomatemática". 1998. Disponível em: <http://sites.uol.com.br/vello/aulas.htm>. Acesso em: 14 dez. 2001.

D'AMBROSIO, U. A relação entre teoria e prática pedagógica na educação infantil e fundamental. 2000. Disponível em: <http://sites.uol.com.br/vello/educa.htm>. Acesso em: 14 dez. 2001.

DEAN, M. Governamentality: power and rule in modern society. London: Sage, 1999.

DELEUZE, G. Qué es un dispositivo? In: Balbier, E. et al. Michel Foucault, filósofo. Barcelona: Gedisa, 1990. p. 155-163.

DELEUZE, G. Foucault. São Paulo: Brasiliense, 1995.

FISCHER, R.M.B. Verdades em suspenso. In: Costa, M.V. (Org.). Caminhos investigativos II: outros modos de pensar e fazer pesquisa em educação. Rio de Janeiro: DP\&A, 2002. p. 49-72.

FISCHER, R.M.B. Mídia, máquinas de imagens e práticas pedagógicas. In: REUNIÃO ANUAL DA ANPED, 29., 2006, Caxambu. Anais... Caxambu: Anped, 2006. (CD-ROM).

FOUCAULT, M. The political technological of individuals. In: Martin, L.H.; Gutman, H.; Hutton, P.H. (Ed.). Technologies of self. Amherst: University of Massachusetts, 1988a. p. 16-49.

FOUCAULT, M. An aesthitics of existence. In: Kritzman, L. (Ed.). Michel Foucault: politics, philosophy, culture. New York: Routledge, 1988b. p. 47-56.

FOUCAULT, M. História da sexualidade I: a vontade de saber. Rio de Janeiro: Graal, 1990.

FOUCAULT, M. Vigiar e punir: história da violência nas prisões. Petrópolis: Vozes, 1995a.

FOUCAULT, M. Sobre a história da sexualidade. In: Foucault, M. Microfísica do poder. Rio de Janeiro: Graal, 1995b. p. 243-276. 
FOUCAULT, M. Tecnologías del yo y otros textos afines. Barcelona: Paidós, 1996.

FOUCAULT, M. A hermenêutica do sujeito. In: Foucault, M. Resumo dos cursos do Collège de France. Rio de Janeiro: Zahar, 1997. p. 117-134.

GILMER, G. Un enfoque etnomatematico al dessarrolo del curriculo. ISGEm Newsletter, v. 5, n. 2, 1991. Disponível em: <http://web.nmsu.edu/ pscott/isgem.htm>. Acesso em: 6 ago. 2000.

GILMER, G. Connecting math practice in and out of school. ISGEm Newsletter, v. 9, n. 2, 1994. Disponível em: <http://web.nmsu.edu/ pscott/isgem.htm>. Acesso em: 6 ago. 2000.

GILMER, G. Una definición de etnomatemáticas. ISGEm Newsletter, v. 11, n. 1, 1995. Disponível em: <http://web.nmsu.edu/ pscott/isgem.htm>. Acesso em: 6 ago. 2000.

GILMER, G. Ethnomathematics: an African American perspective on developing women in mathematics. In: MATHEMATICS EDUCATION AND SOCIETY CONFERENCE (MEAS1), 1., 1998, Nottingham. Conference proceedings. Reino Unido, University of Nottingham, 1998a. Disponível em: <http://www.nottinghan.ac.uk/csme/meas/ measproc.html>. Acesso em:

GILMER, G. Las etnomatemáticas: un enfoque prometedor para desenvolver el liderazgo matemático de las mujeres afroamericanas. In: INTERNATIONAL CONFERENCE ON ETHNOMATHEMATICS, 1., 1998, Granada. Proceedings... Granada: Universidad de Granada, 1998b. (CD-ROM)

ISMAEL, A. El efecto que el uso de juegos culturales Etnomatemática la enseñanza de la probabilidad tiene sobre los resultados, la motivación y las actitudes de los estudiantes frente a las matemáticas. In: INTERNATIONAL CONFERENCE ON ETHNOMATHEMATICS, 1., 1998, Granada. Proceedings... Granada: Universidad de Granada, 1998. (CD-ROM)

KNIJNIK, G. Exclusão e resistência: educação matemática e legitimidade cultural. Porto Alegre: Artes Médicas, 1996.

KUFAKWAMI, D. Matemática y etnomatemática: punto de vista de los estudiantes de Zimbabwe. ISGEm Newsletter, v. 7, n. 1, 1992. Disponível em: <http://web.nmsu. edu/ pscott/isgem.htm>. Acesso em: 6 ago. 2000.

LARROSA, J. Tecnologias do eu e educação. In: Silva, T.T. (Org.). O sujeito da educação: estudos foucaultianos. Petrópolis: Vozes, 1995. p. 35-86.

LARROSA, J. Para que nos sirven los extranjeros? Educação \& sociedade, Campinas, n. 79, p. 67-84, 2002a. 
LARROSA, J. Nietzsche e a educação. Belo Horizonte: Autêntica, $2002 \mathrm{~b}$.

MONTEIRO, A. Etnomatemática: as possibilidades pedagógicas num curso de alfabetização para trabalhadores rurais assentados. 1998. Tese (Doutorado em Educação) - Faculdade de Educação, Universidade Estadual de Campinas, Campinas.

ROSE, N. How should one do the history of the self. In: Rose, N. Inventing our selves: psychology, power and personhood. Cambridge: Cambridge University, 1996.

ROSE, N. Powers of freedom. Cambridge: Cambridge University, 1999.

VEIGA-NETO, A. Educação e governamentalidade neoliberal: novos dispositivos, novas subjetividades. In: Portocarrero, V.; Castelo, G. (Org.). Retratos de Foucault. Rio de Janeiro: Nau, 2000. p. 179-217.

VITHAL, R. Re-searching mathematics education from a critical perspective. In: MATHEMATICS EDUCATION AND SOCIETY CONFERENCE (MEAS2), 2., 2000, Algarve. Conference Proceedings. Algarve, 2000. Disponível em: <http://correio. cc.fc.ul.pt/ jflm/mes2/mes2.html>.

Recebido em junho de 2008.

Aprovado em dezembro de 2008. 